\title{
Jesús Ibáñez: Por una Sociología de la Vida Cotidiana. Siglo XXI, Madrid (España), 2014 (300 páginas).
}

Publicada como libro póstumo, la presente obra constituye una amplia recopilación de textos del sociólogo Jesús Ibáñez (1928-1992), considerado junto con Salvador Giner uno de los padres de la sociología en España. Aunando escritos inéditos con textos ya publicados en periódicos y revistas, se perfilan a lo largo de sus 300 páginas las distintas facetas que caracterizaron la trayectoria profesional del Catedrático de Métodos y Técnicas de Investigación Social de la Universidad Complutense: investigador, docente, publicista, ciudadano.

Por una Sociología de la Vida Cotidiana se enmarca, dentro del conjunto de su obra, en su análisis de la sociedad de consumo (estructura de subordinación característica del capitalismo avanzado), siendo un buen ejemplo de lo que puede considerarse una de sus principales aportaciones a las ciencias sociales, el socioanálisis, su propuesta metodológica que parte del supuesto de que lo objetivo se refleja en, y proyecta desde, lo subjetivo, mientras que el sujeto participa de la investigación como sujeto - en - proceso.

Ya desde su excelente prólogo, obra del periodista y escritor Vicente Verdú, se nos define el presente texto como el libro de Jesús Ibáñez más vivaz, apelativo con el que se condensa su pretensión de abarcar todos los aspectos de la vida cotidiana que analiza, mediante la selección de un apasionante conjunto de escritos que, por su carácter heterogéneo y de innegable actualidad, cumplen precisamente con dicha vocación.

La introducción se completa con una nota aclaratoria de Esperanza Martínez-Conde (viuda de Jesús lbáñez) en la que se relata el azaroso proceso de recopilación y confección de los escritos que finalmente han conformado la obra, y una emotiva presentación por parte de Gérard Imbert, Catedrático de Comunicación audiovisual de la Universidad Carlos III de Madrid y colaborador con Ibáñez en la compilación de la presente obra. Imbert define, en las líneas que preceden al libro que ayudó a gestar, la mirada de lbáñez como "penetrante, cáusticamente crítica, profundamente irónica", presente a lo largo de toda su obra, y determinante de su forma de analizar y explicar el mundo que nos envuelve.

El libro presenta tres grandes apartados que, a modo de puzzle, recogen su disertación sobre algunos de los principales aspectos de la vida cotidiana: la sexualidad, la familia, el consumo, la publicidad, las relaciones de género, etc. Se trata de un libro que busca, como siempre fue objetivo del autor, acercar la labor sociológica al lector, trasladándola de la academia a la sociedad, señalando en el proceso algunas de las claves y mecanismos de la construcción social y política de la realidad en la que vivimos.

En "Vida Cotidiana: Fragmentos de una Realidad Social" se abordan los aspectos más cercanos e íntimos del ciudadano: la casa, la familia, la ciudad y el género, cediendo un importante protagonismo al lenguaje, como elemento conformador del discurso femenino vs masculino, en una búsqueda analítica e intelectual de los resortes que definen y redefinen el papel de la mujer en la sociedad actual.

En sus palabras define el "consumo de signos" que caracteriza nuestra sociedad actual como:[...] "todos los productos de la sociedad de consumo tienen una estructura 
de señuelo: imitación de la forma exterior -superficial- de un producto original, con un contenido -profundo- que nada tiene que ver con él" (p. 19). Alude a la casa donde habitamos, sus estancias y la familia, aspectos sobre los que el autor, más que transmitir conocimientos, invita al lector a reflexionar junto a él.

Reflexión en la que ocupa una parte importante es el proceso de transformación social de la mujer en el sexo dominado, proceso en el que intervienen desde la razón masculina hasta la propia conformación del lenguaje: "La lengua: una máquina machista" (p. 86).

Para concluir, Ibáñez presenta una disertación sobre el futuro de la ciudad, anticipando aquí la visión que del mismo se puede aventurar desde la ciencia ficción, tal y como desarrollará en la tercera parte. Señala Ibáñez:

"[...] El pronóstico de la ciencia ficción es condicional: no tiene la forma "esto va a pasar", sino la forma "esto pasará si tal y tal". Como pronóstico condicional, deja abierta a los propósitos de los sujetos la manipulación de las condiciones” (p. 153).

La segunda parte, titulada "Comunicación y Publicidad: la Producción de la Realidad", se centra en el mundo de la comunicación para hilar una interesante crítica a la sociedad de consumo (ya apuntada en el apartado anterior), desde su teoría sobre los comportamientos e intercambios favorecidos por el capitalismo, como una visión del mundo producida desde fuera del individuo. Idea que se contrapone, al tiempo que completa, la visión del mundo como conjunto de objetos y relaciones, mediante los cuales el sujeto crea una definición concreta de su entorno.

La publicidad es el eje central del análisis, como vehículo a través del cual se hacen llegar a los individuos las construcciones sociales, siendo la construcción de un sentido religioso, como elemento aglutinador de la sociedad, el primero y más genuino ejercicio publicitario. Tras varias revoluciones que supusieron la sustitución de Dios por el Estado, la sustitución capitalista del valor de uso por el valor de cambio, los signos aparecen para simplificar aún más el mensaje y facilitar el proceso de reproducción social. "Los signos están hechos para cubrir la ausencia de las cosas: y, en el límite, nos vedan el acceso a las cosas” (p. 223).

Junto a ella, encontramos un fragmento sobre la evolución del papel de los intelectuales ante la encrucijada que supuso el cambio de régimen de la dictadura en España a la democracia, y ante la nueva coyuntura que supone la nueva ética de la responsabilidad. A este propósito indica:

"Cada vez nos hablan más de la "ética de la responsabilidad": es sólo un maquillaje de la vieja razón de estado. Sólo se tolera una responsabilidad: la responsabilidad conversa. Sólo son "responsables" los intelectuales comprometidos con la realidad -esto es, con la correlación actual en las relaciones de poder [...]“ (p. 252).

Finalmente, la obra se cierra con "Ciencia-Ficción: la Invención de la Realidad”, una aproximación a una perspectiva analítica (más que un mero género literario), que, junto con la antropología, es un recurso frecuente en la obra de Ibáñez. Desde esta visión, y una vez analizado el mundo como construcción en torno a lo cotidiano, así como la representación que de él imponen medios externos como la publicidad, emerge la tercera perspectiva de análisis, donde la realidad aparece como una producción ficticia e imaginada, según proyecta el inconsciente colectivo.

En esta tercera parte, Ibáñez hace un repaso por los autores y obras que mejor han sabido retratar esa capacidad para recrear otras realidades a través del ejercicio de la imaginación, ya que el autor entiende el género como una de las más potentes 
fórmulas de prever mundos futuros: "La ciencia ficción articula: lo teoremático y lo problemático, en su forma; la cualidad vivida y la cualidad pensada, en su contenido" (p. 265).

A lo largo de todo el libro, el autor se esfuerza en señalar las claves y mecanismos de la construcción social y política de la realidad en la que vivimos.

Por una Sociología de la Vida Cotidiana es, en efecto, la obra más viva de Jesús lbáñez, tanto por lo relevante de los temas que trata, como por la valentía de las perspectivas con las que se aproxima a ellos. La heterogeneidad de sus propuestas (las transformaciones de la casa en los últimos siglos, distintas campañas publicitarias o la literatura de ciencia ficción, en la que Ibáñez era un gran experto) no debe llevarnos a engaño, ya que el hilo vertebrador sigue siendo su acerada crítica a la sociedad de consumo, poniendo de relieve el papel de la sociología como instrumento al servicio del cambio social. 